ORIGINAL ARTICLE

\title{
Human herpesviruses -6 and -7 each cause significant neurological morbidity in Britain and Ireland
}

\author{
K N Ward, N J Andrews, C M Verity, E Miller, E M Ross
}

Arch Dis Child 2005;90:619-623. doi: 10.1136/adc.2004.062216

See end of article for authors' affiliations

Correspondence to:

Dr K N Ward, Centre for

Virology, Department of

Infection, Royal Free and

University College Medical

School (UCL campus),

Windeyer Institute of

Medical Sciences, 46

Cleveland Street, London

WIT 4JF, UK; k.n.ward@

ucl.ac.uk

Accepted

8 December 2004
Background: Primary human herpesvirus- 6 and -7 (HHV-6/-7) infections cause febrile illness sometimes complicated by convulsions and rarely encephalopathy.

Aims: To explore the extent of such HHV-6 and -7 induced disease in young children.

Methods: In a three year prospective study in Britain and Ireland, 205 children (2-35 months old) hospitalised with suspected encephalitis and/or severe illness with fever and convulsions were reported via the British Paediatric Surveillance Unit network. Blood samples were tested for primary HHV-6 and -7 infections.

Results: 26/156 (17\%) of children aged 2-23 months had primary infection (11 HHV-6; $13 \mathrm{HHV}-7$; two with both viruses) coinciding with the acute illness; this was much higher than the about three cases expected by chance. All 26 were pyrexial; 25 had convulsions (18 status epilepticus), 11 requiring ventilation. Median hospital stay was 7.5 days. For HHV-6 primary infection the median age was 53 weeks (range 42-94) and the distribution differed from that of uninfected children; for HHV-7, the median was 60 weeks (range 17-102) and the distribution did not differ for the uninfected. Fewer (5/15) children with primary HHV-7 infection had previously been infected with HHV-6 than expected.

Conclusions: Primary HHV-6 and HHV-7 infections accounted for a significant proportion of cases in those $<2$ years old of severe illness with fever and convulsions requiring hospital admission; each virus contributed equally. Predisposing factors are age for HHV-6 and no previous infection with HHV-6 for HHV-7. Children with such neurological disease should be investigated for primary HHV-6/-7 infections, especially in rare cases coinciding by chance with immunisation to exclude misdiagnosis as vaccine reactions.
$\mathrm{P}$ rimary infection with human herpesvirus-6 (HHV-6) may be clinically silent but often causes exanthem subitum (roseola infantum), ${ }^{1}$ a febrile disease of early childhood. ${ }^{2}$ Although usually mild, it was reported, long before the aetiology was known, that convulsions, and rarely encephalopathy, may accompany it. ${ }^{3}$ Since the discovery of HHV-6 in $1986^{4}$ and laboratory diagnosis of primary infection became available, the association with convulsions has been confirmed, ${ }^{5-7}$ and occasional cases of encephalitis in young children have been noted. ${ }^{8}$ Most primary HHV-6 infection occurs in the second six months of life. ${ }^{5}{ }^{10}$ In contrast, primary infection with the closely related human herpesvirus-7 (HHV-7) ${ }^{11}$ usually arises later, in the second and third year. ${ }^{12-14}$ HHV-7 also causes exanthem subitum ${ }^{15}$ and is likewise associated with fever and seizures. ${ }^{13}{ }^{16}$ Encephalitis associated with primary HHV-7 infection in a 19 month old child $^{17}$ and delayed primary HHV-7 infection in an adult accompanied by encephalitis and flaccid paralysis ${ }^{18}$ have been described. Thus, both HHV-6 and -7 are associated with neurological disease but their contribution to the burden of severe forms of such illness in early childhood remained undetermined. We therefore undertook a survey of young children with suspected encephalitis and/or severe illness with fever and convulsions to answer this question.

\section{METHODS}

\section{Patients}

The survey used the monthly surveillance card distributed by the British Paediatric Surveillance Unit (BPSU) to all consultant paediatricians in the UK and Republic of Ireland; BPSU reporting rate $92.7 \%$ (see 16th Annual Report). ${ }^{19}$ Paediatricians were requested to report on the card hospitalised cases of suspected encephalitis and/or severe illness with fever and convulsions in children 2-35 months old, and to telephone the principal investigator to ensure that correctly timed sera (or plasma) samples were sent for diagnosis of primary HHV-6/-7 infections. Regarding age, children up to 3 years were included as this is when most cases of primary HHV-6/-7 infections occur, and the first two months of life were excluded since congenital neurological damage, including inheritable and mechanical causes, usually presents at this time. The reporting case definition excluded the following confirmed causes: pyogenic, hypoxic/ ischaemic, vascular, toxic, metabolic, and neoplastic. We also excluded immunocompromised children. Cases were reported from October 1998 to September 2001 and details of each child's neurological illness were collected using a questionnaire.

Ethics approval was given by the Public Health Laboratory Service Ethics Committee.

\section{Laboratory methods}

HHV-6/-7 IgG and avidity

Samples from the cases were investigated for primary HHV-6/7 infection using authenticated tests for HHV-6/-7 IgG antibody and avidity. ${ }^{1020}$ Tests for antibody avidity have been applied to sera for the diagnosis of many human virus infections. ${ }^{21} 22$ Antibody avidity increases with time after exposure to an immunogen; if the avidity is low this confirms recent primary infection, but if high, primary infection must have occurred in the past.

\section{HHV-6/-7 DNA}

Since transient viraemia occurs in the acute phase of HHV-6 and -7 primary infections, ${ }^{23}{ }^{24}$ tests for HHV-6/-7 DNA in serum or plasma were carried out by polymerase chain reaction ${ }^{25}$ to detect the low level of DNA ${ }^{14} 26$ present briefly as the antibody response commences. 
Table 1 Examples of HHV-6 and -7 antibody responses and detection of DNA in primary infections

\begin{tabular}{|c|c|c|c|c|c|c|c|c|}
\hline \multirow[b]{3}{*}{ Nature of infection* } & \multirow{3}{*}{$\begin{array}{l}\text { Example: } \\
\text { patient no. }\end{array}$} & \multirow{3}{*}{$\begin{array}{l}\text { Days after } \\
\text { admission } \\
\text { sample taken }\end{array}$} & \multicolumn{6}{|c|}{ Plasma or serum } \\
\hline & & & \multicolumn{2}{|c|}{ HHV-6 lgG } & \multirow{2}{*}{$\begin{array}{l}\text { HHV-6 } \\
\text { DNA }\end{array}$} & \multicolumn{2}{|c|}{ HHV-7 IgG } & \multirow{2}{*}{$\begin{array}{l}\text { HHV-7 } \\
\text { DNA }\end{array}$} \\
\hline & & & Titre & Avidity & & Titre & Avidity & \\
\hline $\begin{array}{l}\text { Dual primary HHV-6 and }-7 \text { infections } \\
\text { (patients } 1 \text { and } 2 \text { ) }\end{array}$ & 2 & $\begin{array}{r}1 \\
2 \\
17\end{array}$ & $\begin{array}{l}\mathrm{nt} \\
<16 \\
2048\end{array}$ & $\begin{array}{l}\text { nt } \\
\text { nt } \\
\text { Low }\end{array}$ & $\begin{array}{l}+ \\
\mathrm{nt} \\
\mathrm{nt}\end{array}$ & $\begin{array}{l}<16 \\
\mathrm{nt} \\
256\end{array}$ & $\begin{array}{l}\text { nt } \\
\text { nt } \\
\text { Low }\end{array}$ & $\begin{array}{l}- \\
\text { nt } \\
\text { nt }\end{array}$ \\
\hline $\begin{array}{l}\text { Primary HHV-6 infection without } \\
\text { HHV-7 infection (patients 3-12) }\end{array}$ & 6 & $\begin{array}{r}0 \\
4 \\
10 \\
55\end{array}$ & $\begin{array}{l}<16 \\
<16 \\
2048 \\
512\end{array}$ & $\begin{array}{l}\text { nt } \\
\text { nt } \\
\text { Low } \\
\text { High }\end{array}$ & $\begin{array}{l}+ \\
+ \\
- \\
\text { nt }\end{array}$ & $\begin{array}{l}<16 \\
<16 \\
\text { nt } \\
<16\end{array}$ & $\begin{array}{l}\mathrm{nt} \\
\mathrm{nt} \\
\mathrm{nt} \\
\mathrm{nt}\end{array}$ & $\begin{array}{l}- \\
- \\
- \\
n+\end{array}$ \\
\hline $\begin{array}{l}\text { Primary HHV-6 infection with past } \\
\text { HHV-7 infection (patient 13) }\end{array}$ & 13 & $\begin{array}{r}3 \\
14\end{array}$ & $\begin{array}{l}32 \\
128\end{array}$ & $\begin{array}{l}\text { nt } \\
\text { Low }\end{array}$ & $\begin{array}{l}+ \\
-\end{array}$ & $\begin{array}{l}128 \\
128\end{array}$ & $\begin{array}{l}\text { High } \\
\text { High }\end{array}$ & - \\
\hline $\begin{array}{l}\text { Primary HHV-7 infection without } \\
\text { HHV-6 infection (patients } 15-22 \dagger \text { ) }\end{array}$ & 21 & $\begin{array}{r}4 \\
11 \\
41 \\
168\end{array}$ & $\begin{array}{l}<16 \\
16 \\
<16 \\
16\end{array}$ & $\begin{array}{l}\mathrm{nt} \\
\mathrm{nt} \\
\mathrm{nt} \\
\mathrm{nt}\end{array}$ & $\begin{array}{l}- \\
- \\
\text { nt } \\
-\end{array}$ & $\begin{array}{l}<16 \\
512 \\
512 \\
512\end{array}$ & $\begin{array}{l}\text { nt } \\
\text { Low } \\
\text { Low } \\
\text { High }\end{array}$ & $\begin{array}{l}+ \\
- \\
\text { nt } \\
-\end{array}$ \\
\hline $\begin{array}{l}\text { Primary HHV-7 infection with past } \\
\text { HHV-6 infection (patients } 14 \ddagger, 23-26 \text { ) }\end{array}$ & 23 & $\begin{array}{r}3 \\
15 \\
96 \\
119\end{array}$ & $\begin{array}{l}512 \\
8192 \\
1024 \\
512\end{array}$ & $\begin{array}{l}\text { High } \\
\text { High } \\
\text { High } \\
\text { High }\end{array}$ & $\begin{array}{l}- \\
\text { nt } \\
- \\
-\end{array}$ & $\begin{array}{l}64 \\
8192 \\
4096 \\
256\end{array}$ & $\begin{array}{l}\text { Low } \\
\text { Low } \\
\text { Low } \\
\text { High }\end{array}$ & $\begin{array}{l}+ \\
\mathrm{nt} \\
- \\
\mathrm{nt}\end{array}$ \\
\hline
\end{tabular}

*The criteria for primary and past infection, and uninfected are described in the Methods.

tPatient 20 had primary HHV-7 infection pinpointed to the disease episode by the detection of HHV-7 DNA in the acute CSF rather than serum (Methods b). †Patient 14 was only 4 months old and HHV-6 lgG of high avidity was consistent with either persisting maternal antibody or past HHV-6 infection.

nt, not tested.

\section{Definitions}

\section{Onset of illness}

The day of hospital admission.

\section{Acute serum}

Taken within nine days of hospital admission.

Early convalescent serum

Taken within 10-21 days of hospital admission.

\section{Late convalescent serum}

Taken more than 21 days after hospital admission.

\section{Primary HHV-6/-7 infection}

Primary infection coinciding with the onset of neurological illness was identified where:

(a) The acute sample was either seronegative or had low avidity antibody for the particular virus, but contained the viral $\mathrm{DNA}^{14}$ pinpointing the start of the primary infection

(b) There was seroconversion (i) to low avidity IgG antibody (including rising titre $\geqslant 4$-fold) to the particular virus between acute and early convalescent sera; ${ }^{14}{ }^{140}$ or (ii) to low or high avidity IgG antibody to the particular virus between acute and late convalescent sera but also with the viral DNA in the acute serum sample pinpointing the start of primary infection.

\section{Past HHV-6/-7 infection}

Where antibody was detected but the results did not meet the criteria for primary infection, it was assumed that the primary infection had occurred some weeks before the onset of illness. This applied particularly to cases where high avidity IgG was detected in serum or plasma taken within six weeks of the onset of illness since antibody avidity matures from low to high in about six weeks after primary infection.

\section{Uninfected with HHV-6/-7}

This was defined by the absence of antibody and DNA for the particular virus.

\section{Statistical analysis}

The aim of the analysis was to investigate whether there is evidence of a causal relation between neurological disease and HHV-6 or HHV-7 infection, and also whether this relation varies by age. A further aim was to investigate whether past infection by HHV-6 could protect against a risk of disease due to HHV-7 (and vice versa).

To carry out the analysis it was first necessary to set up a model for the acquisition of HHV-6 or HHV-7. Data for children aged over 20 weeks were aggregated into 20 week age groups. The proportion of cases with past HHV-6 (or HHV-7) infection out of those with past or no infection was used to estimate a constant force of infection, ${ }^{27}$ that is, rate of acquisition in susceptible children $(\lambda /$ week). This simple model was fitted using maximum likelihood methods. Because this constant force of infection model provided a good fit to the data the following analyses could then be performed:

(i) Investigating the relation between neurological disease and HHV-6 or HHV-7. If it is assumed (conservatively) that primary HHV-6 (or HHV-7) infections occur in a two week window, then, with the assumption of no relation between HHV-6 (or HHV-7) and neurological disease, the ratio of acute primary infection cases to uninfected cases is expected to be approximately $2 \lambda$. The observed number of primary infections was compared to the expected number using a Poisson distribution with mean $2 \lambda$. The incidence rate ratio (observed/expected) was also calculated with 95\% confidence intervals.

(ii) Assessing the age of the cases with primary infection. If the risk of neurological disease from HHV-6 (or HHV-7) primary infection was not dependent on age, then the ratio of primary infection cases to uninfected cases should not vary by age group (that is, ages of negative and primary cases should be similar). This was tested using Fisher's exact test.

(iii) Assessing the effect of past HHV-7 infection on the risk from HHV-6 (and vice versa). This can be investigated by 
comparing the ratio of primary HHV-6 infection cases to uninfected HHV-6 cases in those with past and uninfected HHV-7 status. If past HHV-7 infection protects against a risk from primary HHV-6 infection, then we would expect the ratio of primary infections to those uninfected with HHV-6 to be smaller in those with past HHV-7 infection than in those uninfected with HHV-7. This was tested using $\chi^{2}$ and Fisher's exact tests.

\section{RESULTS}

Of all the cases fulfilling the reporting case definition and where the paediatrician had returned a clinical questionnaire, 205 children aged between 2 and 35 months (five with two episodes-that is, 210 cases) were tested for HHV-6 and -7 infections as appropriately timed serum samples were available.

All 26 children found to have primary HHV-6 and/or -7 infections coinciding with their presenting neurological illness were $<2$ years old. Since 156 of the 205 children reported were of this age, the proportion with primary infection was $26 / 156$ (17\%; $95 \%$ CI $11-23 \%$ ). There were 13 cases of HHV-6 and 15 of HHV-7; 11 children with HHV-6, 13 with HHV-7, and 2 with both viruses. Table 1 shows examples of antibody responses and detection of DNA in the primary infections. Of the 13 primary HHV-6 infections, HHV-6 DNA was detected in the acute sample in 10 cases (primary infection definition (a), see Methods). In two cases convalescent sample(s) were not available and primary infection rested solely on definition (a), but the remaining 11 of the 13 cases fulfilled definition (b) (see Methods) since both acute and convalescent samples were available. Similarly, of the 15 primary HHV-7 infections, for 10 HHV-7 DNA was detected in the acute sample; four were defined as primary infection solely by definition (a) and the remaining 11 of the 15 cases fulfilled definition (b) since both acute and convalescent samples were available.

Results of HHV-6/-7 antibody and DNA tests were used not only to identify the 26 primary infections but also to classify the remaining cases as having either past infection, or being uninfected (see definitions in Methods). Table 2 shows the status of HHV-6/7 infections by age, but note that maternal antibody is present over the first few months of life and may be wrongly interpreted as past infection. Therefore, an arbitrary point of $>20$ weeks was adopted to define past infection since most children are seronegative by about this time. ${ }^{14}$ The median age of the 26 children with primary HHV-6 and/or -7 infection, was 59 weeks (range 17-102). The median age of the 13 children with primary HHV-6 infection was 53 weeks (42-94) compared with 60 weeks (range 17-102) for the 15 children with primary HHV-7 infection. Using the cases aged over 20 weeks, Fisher's exact test compared the age distribution of primary infections with that of the uninfected cases - that is, those at risk of primary infection (see Methods, statistical analysis ii). This showed that HHV-6 infected children had a significantly different age distribution from the uninfected cases $(p=0.015)$, mainly due to the large number of primary cases in the 41-60 week age group. There was no difference for HHV-7 $(\mathrm{p}=0.71)$.

Table 2 also shows the prevalence of infection (number of cases with past infection/number with past infection plus uninfected $\times 100$ ) according to age. This was used to estimate the rates at which an individual child acquired infection with HHV-6/-7, assuming that the rate was constant and independent of age. This model gave a good fit to the observed prevalence (fig 1); for this analysis, cases with primary infection were excluded as were those aged 20 weeks or less. Once the rate of acquisition of infection was known $(\lambda=1.63 \% /$ week for HHV-6 and $0.65 \% /$ week for HHV-7; fig 1), it could be calculated (see Methods, statistical analysis i) that 1.66 primary HHV-6 infections and $1.34 \mathrm{HHV}-7$ should be encountered among the children if there were no association with disease. The actual numbers of HHV-6/-7 primary infections were much higher, being 13 and 14 respectively (note patient $14,<20$ weeks old, was excluded from these numbers). The probabilities (p) of observing so many cases of HHV-6 and HHV-7 primary infections by chance were $<0.001$ for each virus and the incidence rate ratios with $95 \%$ CIs were 7.8 (4.2 to 13.3 ) and 10.4 (5.8 to 17.2) respectively.

Of the 13 primary HHV-6 infections (table 1), in 12 the child had not been previously infected with HHV-7 (patients 1-12) and the remaining case (patient 13) had evidence of past HHV-7 infection. Similarly of the 15 primary HHV-7 infections (table 1), in 10 the child had not been previously infected with HHV-6 (patients 1, 2, 15-22); in a further case (patient 14 who was $<20$ weeks old), there was high avidity HHV-6 IgG consistent with persisting maternal antibody or past HHV-6 infection; and the remaining four had evidence of past HHV-6 infection (patients 23-26). Thus, in 20 of the 26 primary infections the child had not been previously infected with either virus. Table 3 shows the combined HHV6/-7 status for each case aged over 20 weeks. From this it can be calculated (see Methods, statistical analysis iii) that there was a tendency for the ratio of primary HHV-7 infections to those uninfected with HHV-7 to be smaller in those with past HHV-6 infection than in those uninfected with HHV-6 (4/52 and $8 / 32$, respectively; $p=0.06$ ) but there was no such tendency for primary HHV-6 (1/9 and 10/32, respectively; $\mathrm{p}=0.67)$.

Table 2 Status of HHV-6 and -7 infections according to age

\begin{tabular}{|c|c|c|c|c|c|c|c|c|c|c|}
\hline \multirow[b]{2}{*}{$\begin{array}{l}\text { Age } \\
\text { (weeks) }\end{array}$} & \multicolumn{5}{|c|}{ HHV-6 infection* } & \multicolumn{5}{|c|}{ HHV-7 infection* } \\
\hline & Uninfected & Primary & Past & Uninterpretable† & $\begin{array}{l}\text { Prevalence } \\
\% \ddagger\end{array}$ & Uninfected & Primary & Past & Uninterpretable† & $\begin{array}{l}\text { Prevalence } \\
\% \ddagger\end{array}$ \\
\hline $9-20$ & 10 & 0 & 9 & 1 & $-\S$ & 14 & 1 & 5 & 0 & $-\S$ \\
\hline $21-40$ & 14 & 0 & 8 & 1 & 36 & 16 & 2 & 5 & 0 & 24 \\
\hline $41-60$ & 10 & 8 & 14 & 1 & 58 & 21 & 5 & 7 & 0 & 25 \\
\hline $61-80$ & 17 & 2 & 24 & 1 & 59 & 23 & 5 & 14 & 2 & 38 \\
\hline $81-100$ & 4 & 3 & 22 & 4 & 85 & 20 & 1 & 12 & 0 & 38 \\
\hline $101-120$ & 3 & 0 & 22 & 2 & 88 & 13 & 1 & 13 & 0 & 50 \\
\hline $121-140$ & 2 & 0 & 15 & 1 & 88 & 5 & 0 & 12 & 1 & 71 \\
\hline $141-156$ & 1 & 0 & 10 & 1 & 91 & 5 & 0 & 7 & 0 & 58 \\
\hline Total & 61 & 13 & 124 & 12 & & 117 & 15 & 75 & 3 & \\
\hline
\end{tabular}

*The criteria for primary and past infection, and uninfected are described in the Methods. †Sample unsuitably timed for interpretation of result.

$\ddagger$ Number of cases with past infection/number with past infection plus uninfected $\times 100$.

$\S F$ r cases $\leqslant 20$ weeks, prevalence not calculated because of the possibility of persisting maternal antibody being interpreted as past infection. 


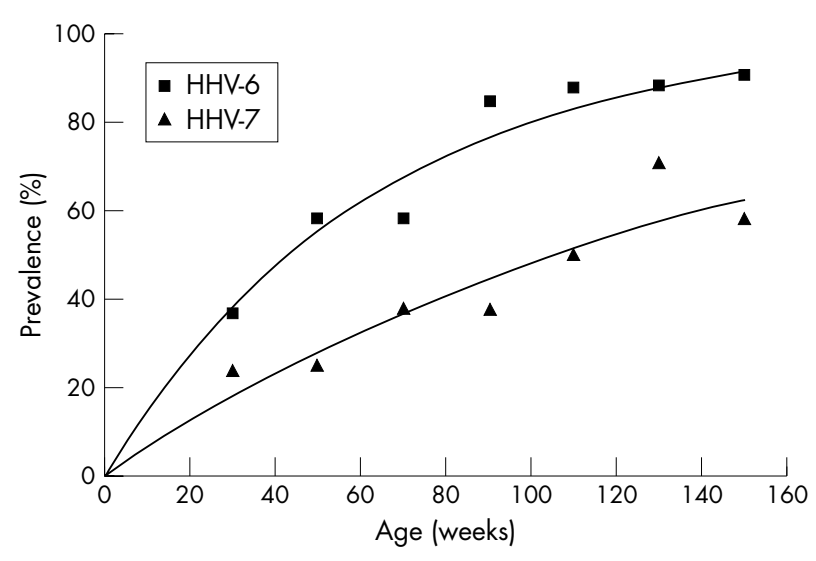

Figure 1 Prevalence of HHV- 6 and -7 infections in relation to age together with fitted prevalence based on a constant rate of acquisition. Data from all children $>20$ weeks old without primary infection (see table 2 for numbers in each age group). HHV- 6 and HHV-7 prevalence $=$ number of cases with past infection/number with past infection plus uninfected $\times 100$, given at midpoint for each age group. Curves represent fitted prevalence for HHV-6/-7.

The clinical information for all 26 children with primary infections was reviewed. CSF from 21 children had been tested at the admitting hospital for herpes simplex virus DNA, with negative results, including the only two CSFs containing more than $5 \times 10^{6}$ white blood cells/l. Primary HHV -6 and -7 infections had similar clinical characteristics (table 4) and the median number of days in hospital was 7.5 (range 1-26). All the children were pyrexial, all but one had convulsions, but only half had a rash. The most common presentation (18/26) was status epilepticus-that is, convulsions lasting more than 30 minutes. Eleven children were ventilated and sedated. All but four of the children were treated with acyclovir but no other antiviral drugs were used. As regards outcome, the survey was not designed for long term clinical follow up, but did include the question "Was there full recovery in the immediate short term?", which was the case for 20 children.

\section{DISCUSSION}

Determination of primary infection by a given agent concurrent with a set of symptoms has been used to identify the aetiology of many infectious diseases. The recognition of HHV-6 and HHV-7 as the two alternative causes of exanthem subitum was achieved in just this way. ${ }^{15}$ Similarly, we have shown that an appreciable number of cases of suspected encephalitis and/or severe convulsions with fever in children aged up to 3 years coincide with primary HHV-6 and -7 infections. However, since most children undergo primary infection with these two viruses during this period (fig l), we calculated the likelihood of identifying so many primary infections at the start of the neurological illness by chance. The results for each virus excluded chance since the number

Table 3 Combined HHV- 6 and -7 status of the 176 cases $>20$ weeks old with results for both infections

\begin{tabular}{|c|c|c|c|c|}
\hline & & \multicolumn{3}{|c|}{ HHV-6 infection } \\
\hline & & Uninfected* & Primary* & Past $^{*}$ \\
\hline $\begin{array}{l}\text { HHV-7 } \\
\text { infection }\end{array}$ & $\begin{array}{l}\text { Uninfected* } \\
\text { Primary* } \\
\text { Past }^{*}\end{array}$ & $\begin{array}{l}32 \\
8 \\
9\end{array}$ & $\begin{array}{l}10 \\
2 \\
1\end{array}$ & $\begin{array}{l}52 \\
4 \\
58\end{array}$ \\
\hline
\end{tabular}

*The criteria for primary and past infection, and uninfected are described in the Methods. of cases was much higher than expected ( $p<0.001$ ); almost all cases were therefore directly attributable to the primary infections.

Although severe neurological disease due to primary HHV-6 or -7 has occasionally been reported, this is the first demonstration of such an important contribution to significant morbidity in early childhood. Thus, our prospective survey shows that primary infection with these two viruses is responsible for suspected encephalitis and/or severe convulsions with fever in about $17 \%$ of children in the first two years of life. Both HHV-6 and -7 contribute equally to the burden of disease, a hitherto unsuspected finding. However, it should be noted that, although the coverage was excellent, ${ }^{19}$ the number of cases reported is most likely an underestimate of the incidence; our study was not designed to give full ascertainment of cases. As regards clinical features, there was no difference between the neurological effects of primary infection with either virus, the most common feature being the neurological emergency of status epilepticus associated with fever (defined in Verity ${ }^{28}$ ). As noted by us here and previously reported by others, ${ }^{5}{ }^{13}$ primary infection is not always associated with a rash. Almost half of the children presented with encephalopathy, but cerebral dysfunction might have resulted either from the management of the convulsions, including drug therapy and sedation for ventilation, or from the underlying pathology.

Primary HHV-6 infection usually occurs in infancy, peaking at 6-8 months, ${ }^{5}{ }^{10}$ whereas HHV-7 infection usually occurs later. ${ }^{12-14}$ This temporal sequence is well illustrated by our data (fig 1), but notably it did not apply in the children with acute primary HHV-6 and -7 infections where the median age was 1 year for both. A similar median age has already been reported for HHV-6 associated seizures in a community based study, ${ }^{5}$ and this has now been confirmed by us for more severe HHV-6 induced neurological disease requiring hospitalisation.

As regards predisposing factors, it appears that the risk of primary HHV-6 infection causing neurological illness is age dependent, whereas for HHV-7 it does not seem to be. For HHV-7 the absence of previous HHV-6 infection may predispose to neurological morbidity, perhaps because previous HHV-6 infection affords some protection due to limited immunological cross reactivity between the viruses. ${ }^{29}{ }^{30}$

Table 4 Comparison of clinical characteristics of patients with primary $\mathrm{HHV}-6$ versus $\mathrm{HHV}-7$ infection

\begin{tabular}{lll}
\hline & HHV-6 & HHV-7 \\
\hline No. of children & $13^{*}$ & $15^{*}$ \\
Median days in hospital (range) & $9(3-26)$ & $5(1-21)$ \\
Maximum temperature, ${ }^{\circ} \mathrm{C}$ (range) & $39(37.8-40)$ & $38.7(37.8-40.2)$ \\
No. with rash & 9 & 4 \\
No. with convulsions (no. with & & \\
$\geqslant 24$ h encephalopathy) & $1(1)$ & 0 \\
None & $2(2)$ & 1 \\
$<15$ min & $3(2)$ & $1 \dagger$ \\
$15-30$ min & $7(2)^{*}$ & $13(4)^{*} \ddagger$ \\
$>30$ min (status epilepticus) & & \\
No. ventilated and sedated & $4 \S$ & $1^{* *}$ \\
For control of status epilepticus & $4 \S$ \\
Other reason & 2 - & \\
\hline
\end{tabular}

*Includes two dual HHV-6 and -7 infections.

†One with Todd's paresis and previous developmental delay and microcephaly.

fOne with suspected myoclonic jerks reported previously with convulsions and fever; one with previous infantile spasms; one with previous herpes simplex encephalitis and consequent non-febrile seizures.

§lncludes one dual HHV-6 and -7 infection.

-One for respiratory arrest and one for encephalopathy

**One ventilated for CT scan. 


\section{What is already known on this topic}

- Primary HHV-6 infection sometimes causes exanthem subitum (roseola infantum) but otherwise the infection is silent or accompanied by fever without rash. Similarly primary HHV-7 infection occasionally causes exanthem subitum

- Primary infection with either virus is sometimes complicated by convulsions and rarely encephalopathy

- Although severe neurological disease due to primary HHV-6 or -7 has been reported rarely, the burden of this kind of illness has not previously been investigated

\section{What this study adds}

- Primary HHV-6 and -7 infections together are responsible for about $17 \%$ of hospital admissions in Britain and Ireland in the first two years of life for suspected encephalitis and/or severe illness with fever and convulsions, especially status epilepticus

- HHV-6 and -7 are both equally important causes of such illness, a hitherto unsuspected finding. The significant contribution of $\mathrm{HHV}-7$ is recognised for the first time

- Young children with such neurological disease should be investigated for primary HHV-6 and -7 infections

- Since the burden of disease due to HHV-6 and -7 occurs around 1 year of age at the time at when MMR vaccine is given, it is especially important to test for primary HHV-6 and -7 infection to exclude misdiagnosis of neurological disease as vaccine reactions

As HHV-6 and -7 are shown by our survey to be equally important causes in young children of suspected encephalitis and/or severe convulsions with fever requiring hospital admission, such cases must in future be investigated for primary infection by these viruses. Finally, since the burden of severe neurological disease due to primary HHV-6 and -7 infection occurs around 1 year of age, just when the measles, mumps, rubella (MMR) vaccine is administered, recent immunisation is likely occasionally to coincide by chance with neurological complications induced by primary HHV-6 and -7 infections, rather than the vaccine. Indeed it is important that such cases after any vaccination in early life should be investigated for causative HHV-6 or -7 primary infection, especially if associated with fever or convulsions, in order to exclude misdiagnosis as vaccine reactions.

\section{ACKNOWLEDGEMENTS}

The authors thank the Wellcome Trust for generous support for the survey of encephalitis in young children (project grant 051350/Z), and the British Paediatric Surveillance Unit for invaluable assistance and access to its network in Britain and the Republic of Ireland. They are also most grateful to the many paediatricians, microbiologists, and virologists who took time and trouble to send reports and specimens in support of the survey, to Ms Gloria Charter for excellent assistance as data coordinator for the survey, and to Mr X Couto Parada and Mr A D Thiruchelvam for invaluable technical assistance.

\section{Authors' affiliations}

K N Ward, Department of Virology, Royal Free and University College Medical School, Windeyer Institute of Medical Sciences, London, UK
N J Andrews, E Miller, Communicable Disease Surveillance Centre,

London, UK

C M Verity, Child Development Centre, Addenbrooke's Hospital, Cambridge, UK

E M Ross, Child Studies Department, King's College, London, UK

Competing interests: none declared

\section{REFERENCES}

1 Yamanishi K, Okuno T, Shiraki K, et al. Identification of human herpesvirus-6 as a causal agent for exanthem subitum. Lancet 1988;1:1065-7.

2 Zahorsky J. Roseola infantilis. Pediatrics 1910;22:60-6.

3 Berenberg W, Wright S, Janeway CA. Roseola infantum (exanthem subitum). N Engl J Med 1949;241:253-9.

4 Salahuddin SZ, Ablashi DV, Markham PD, et al. Isolation of a new virus, $\mathrm{HBLV}$, in patients with lymphoproliferative disorders. Science 1986;234:596-601.

5 Hall CB, Long CE, Schnabel KC, et al. Human herpesvirus- 6 infection in children. A prospective study of complications and reactivation. N Engl J Med 1994;331:432-8

6 Ward KN, Gray JJ. Primary human herpesvirus- 6 infection is frequently overlooked as a cause of febrile fits in young children. J Med Virol 1994;42:119-23.

7 Asano Y, Yoshikawa T, Suga S, et al. Clinical features of infants with primary human herpesvirus 6 infection (exanthem subitum, roseola infantum). Pediatrics 1994;93:104-8.

8 Suga S, Yoshikawa T, Asano Y, et al. Clinical and virological analyses of 21 infants with exanthem subitum (roseola infantum) and central nervous system complications. Ann Neurol 1993;33:597-603.

9 Yoshikawa T, Suga S, Asano Y, et al. Distribution of antibodies to a causative agent of exanthem subitum (human herpesvirus-6) in healthy individuals. Pediatrics 1989;84:675-7.

10 Ward KN, Gray JJ, Fotheringham MW, et al. IgG antibodies to human herpesvirus- 6 in young children: changes in avidity of antibody correlate with time after infection. J Med Virol 1993;39:131-8.

11 Frenkel N, Schirmer EC, Wyatt LS, et al. Isolation of a new herpesvirus from human CD4+ T cells [published erratum appears in Proc Natl Acad Sci U S A 1990;87:7797]. Proc Natl Acad Sci U S A 1990;87:748-52.

12 Torigoe S, Kumamoto T, Koide W, et al. Clinical manifestations associated with human herpesvirus 7 infection. Arch Dis Child 1995;72:518-19.

13 Caserta MT, Hall CB, Schnabel K, et al. Primary human herpesvirus 7 infection: a comparison of human herpesvirus 7 and human herpesvirus 6 infections in children. J Pediatr 1998; 133:386-9.

14 Ward KN, Turner DJ, Couto Parada X, et al. Use of immunoglobulin G antibody avidity for differentiation of primary human herpesvirus 6 and 7 infections. J Clin Microbiol 2001;39:959-63.

15 Tanaka K, Kondo T, Torigoe S, et al. Human herpesvirus 7: another causal agent for roseola (exanthem subitum). J Pediatr 1994;125: 1-5.

16 Torigoe S, Koide W, Yamada M, et al. Human herpesvirus 7 infection associated with central nervous system manifestations. J Pediatr 1996;129:301-5.

17 van den Berg JS, van Zeiil JH, Rotteveel JJ, et al. Neuroinvasion by human herpesvirus type 7 in a case of exanthem subitum with severe neurologic manifestations. Neurology 1999;52:1077-9.

18 Ward KN, Kalima P, MacLeod KM, et al. Neuroinvasion during delayed primary HHV-7 infection in an immunocompetent adult with encephalitis and flaccid paralysis. J Med Virol 2002;67:538-41.

19 British Paediatric Surveillance Unit. 16th annual report 2001-2002, http:// www.rcpch.ac.uk/publications/BPSU/Annual_report_2002.PDF (accessed 18 May 2004).

20 Ward KN, Couto Parada X, Passas J, et al. Evaluation of specificity and sensitivity of indirect immunofluorescence tests for lgG to human herpesviruses-6 and -7. J Virol Methods 2002;106:107-13.

21 Hedman K, Lappalainen M, Söderlund $M$, et al. Avidity of IgG in serodiagnosis of infectious diseases. Rev Med Microbiol 1993;4:123-9.

22 Goldblatt D. Simple solid phase assays of avidity. In: Johnstone A, Turner MW, eds. Immunochemistry 2: a practical approach. Oxford: IRL Press at Oxford University Press, 1997:31-51.

23 Asano Y, Yoshikawa T, Suga S, et al. Viremia and neutralizing antibody response in infants with exanthem subitum. J Pediatr 1989;114(4 pt 1):535-9.

24 Asano Y, Suga S, Yoshikawa T, et al. Clinical features and viral excretion in an infant with primary human herpesvirus 7 infection. Pediatrics 1995;95: 187-90.

25 Kidd IM, Clark DA, Bremner JA, et al. A multiplex PCR assay for the simultaneous detection of human herpesvirus 6 and human herpesvirus 7 , with typing of HHV-6 by enzyme cleavage of PCR products. J Virol Methods 1998;70:29-36.

26 Chiu SS, Cheung CY, Tse CY, et al. Early diagnosis of primary human herpesvirus 6 infection in childhood: serology, polymerase chain reaction, and virus load. J Infect Dis 1998;178:1250-6.

27 Anderson RM, May RM. In: Anderson RM, May RM, eds. Infectious diseases of humans: dynamics and control. Oxford: Oxford University Press, 1991, 49-51, 160-70.

28 Verity CM. Status epilepticus associated with fever. In: Engel J, Pedley TA, eds. Epilepsy: a comprehensive textbook. Philadelphia: Lippincott-Raven, 1997:731-9.

29 Black JB, Schwarz TF, Patton JL, et al. Evaluation of immunoassays for detection of antibodies to human herpesvirus 7. Clin Diagn Lab Immunol 1996;3:79-83

30 Black JB, Pellett PE. Human herpesvirus 7. Rev Med Virol 1999;9:245-62. 